\title{
KNOWLEDGE, ATTITUDE AND PRACTICE OF PHARMACOVIGILANCE AMONG OPERATORS OF PHARMACIES AND PATENT MEDICINE STORES IN SOKOTO METROPOLIS, NIGERIA
}

\author{
Awosan $\mathrm{KJ}^{1}{ }^{*}$, Yunusa $\mathrm{A}^{\mathbf{2}}$, Yakubu $\mathbf{I}^{\mathbf{1}}$, Yunusa KK ${ }^{\mathbf{1}}$, Auwal $\mathrm{AM}^{\mathbf{1}}$ \\ ${ }^{1}$ Department of Community Health, Usmanu Danfodiyo University, Sokoto, Nigeria. \\ ${ }^{2}$ Department of Pharmacology, Usmanu Danfodiyo University, Sokoto, Nigeria.
}

\begin{abstract}
Background: The weak pharmacovigilance (PV) systems in many developing countries of the world have undoubtedly hampered the global quest for safe drug use. Operators of pharmacies and patent medicine stores have important roles to play in developing the PV systems in these countries being the main source of medicines for acute conditions. This study aimed to assess the knowledge, attitude and practice of pharmacovigilance among operators of pharmacies and patent medicine stores in Sokoto metropolis, Nigeria. Materials and Methods: A cross-sectional study was conducted among 249 operators of pharmacies and patent medicine stores selected by a multistage sampling technique. Data were collected with a set of pretested self-administered, semi-structured questionnaire.

Results: Although, the majority, $173(69.5 \%)$ of the 249 respondents were aware of PV, less than a fifth (17.3\%) had good knowledge of it. Despite positive attitude towards PV, only about half, $56(52.3 \%)$ of the 107 respondents that had observed adverse drug reactions (ADRs) in clients reported; and of these, only about a tenth $(12.8 \%)$ formally reported to the organization in charge of PV. The most commonly cited reasons for non-reporting were that they did not know where and how to report (51.0\%), and unavailability of reporting forms $(23.5 \%)$.

Conclusion: This study showed poor knowledge of PV and sub-optimal ADRs reporting despite positive attitude towards it by operators of pharmacies and patent medicine stores in Sokoto metropolis, Nigeria. Sensitization of the populace and training of healthcare providers on PV and ADRs reporting are necessary for revitalizing the PV system in Sokoto State, Nigeria.
\end{abstract}

Keywords: Pharmacovigilance, knowledge, attitude, practice

Article Info: Received 04 Aug, 2018; Review Completed 27 Aug 2018; Accepted 27 Aug 2018; Available online 15 Sep 2018

\section{Cite this article as:}

Awosan KJ, Yunusa A, Yakubu I, Yunusa KK, Auwal AM, Knowledge, attitude and practice of pharmacovigilance among operators of pharmacies and patent medicine stores in Sokoto metropolis, Nigeria. Journal of Drug Delivery and Therapeutics. 2018; 8(5):358-364 DOI: http://dx.doi.org/10.22270/jddt.v8i5.1881

\section{*Address for Correspondence:}

Dr Awosan K.J., Department of Community Health, College of Health Sciences, Usmanu Danfodiyo University, Sokoto, Nigeria.

\section{INTRODUCTION}

Although, pharmacovigilance (PV) is undoubtedly an effective strategy for enhancing patients' safety, as it concerns the science and activities relating to the detection, assessment, understanding and prevention of adverse effects or any other drug-related problem, ${ }^{1}$ the weak PV systems in many developing countries of the world continue to hamper the global quest for safe drug use.

Timely and comprehensive adverse drug reaction (ADR) reporting undoubtedly constitutes the main pillar of a strong PV system. A cause for concern is the fact that while the prevalence of ADR (defined as a response to a drug which is noxious and unintended, and which occurs at doses normally used in man for the prophylaxis, diagnosis, or therapy of disease, or for the modification of physiological function) continues to rise globally and has become one of the leading cause of morbidity and mortality, it is poorly under-reported worldwide, particularly in the developing countries. ${ }^{2-4}$

The low ADRs reporting rates in many developing countries have been attributed to the poor awareness / knowledge of PV and ADRs reporting among the 
healthcare professionals in these countries. In a study among healthcare professionals in Saudi Arabia, ${ }^{5}$ most of the respondents $(62.5 \%)$ were unaware of PV, less than half of respondents knew the correct definition of PV $(44.3 \%)$ and ADRs $(46.1 \%)$, and most of them $(88.8 \%)$ had never reported, submitted or identified any ADR reports despite the fact that most of them showed positive attitude to $\mathrm{PV}$ and $\mathrm{ADR}$ reporting. Another study among pharmacists in Jordan ${ }^{6}$ reported that only $25.5 \%$ of the respondents knew the correct definition of $\mathrm{PV}$, most of them were unaware of the existence of any PV centre in the country $(84.5 \%)$, and of an official standardized form for reporting ADRs (71.5\%). In addition, while $91.2 \%$ of respondents had noticed at least one ADR in a patient per year, only $19.5 \%$ had ever reported an ADR.

The state of the PV systems in the sub-Saharan African countries (including Nigeria) is very precarious; a comprehensive assessment of the PV systems and their performance in 46 countries across the continent showed that $87 \%$ of the countries do not have a functional PV system, $59 \%$ do not have a national policy related to medicine safety, $70 \%$ lack legislation to monitor adverse events, and $26 \%$ do not have a national PV centre. In addition, although $74 \%$ have spontaneous adverse event reporting systems, less than $50 \%$ monitor product quality, medication errors or treatment failures through the existing systems; and reporting rates were low with only 2 countries collecting more than 100 reports per million population in 2010 .

This is corroborated by the generally poor knowledge of PV and low ADRs reporting obtained in studies conducted across the continent. In a study among healthcare workers at the Mulago National Referral and Teaching Hospital in Uganda, ${ }^{8}$ only 37.7, 18.4 and $16.6 \%$ of respondents knew the tools used in ADR reporting, where to report ADR, and had ever reported an ADR respectively. Another study among community and hospital pharmacists in a selected district of North West province, South Africa, ${ }^{9}$ reported that less than half of respondents $(46.1 \%)$ knew the correct definition of $\mathrm{PV}$, and despite the fact that most respondents (79.4\%) regarded PV as a valuable tool, only $44.1 \%$ had ever reported an ADR. The enormity of the situation in sub-Saharan Africa becomes glaringly obvious and alarming with the deplorable state of the healthcare services across the continent, and with operators of patent medicine stores being the main care providers for common but potentially deadly illnesses in the respective populations across the continent; in addition to the prevalent inappropriate drug dispensing practices by them, and the fact that their practices are largely unregulated. ${ }^{10}$

Similar to the situation across the continent, operators of patent medicine stores are the main source of medicine for acute conditions in Nigeria, ${ }^{11}$ and they often engage in inappropriate drug dispensing practices as their practices are largely unsupervised and unregulated in the country. ${ }^{11,12}$ Despite the large population of clientele that patronize the patent medicine stores and the risks posed by the inappropriate drug dispensing practices of the operators, previous studies in Nigeria were focused on healthcare professionals (including doctors, nurses and pharmacists), and there is limited information on the knowledge and practice of PV and ADRs reporting among the operators of patent medicine stores in the country.

Strikingly, the previous studies in Nigeria generally reported poor knowledge and practice of PV and ADRs reporting. A study among 350 resident doctors in 4 teaching hospitals in Edo and Lagos States of Nigeria ${ }^{13}$ reported that most of them $(78.1 \%)$ had inadequate knowledge of PV (78.1\%), and were unaware of the yellow form for reporting ADRs (71.2\%). And while most of them $(92.4 \%)$ had observed ADRs in the course of their training and practice, only $25.5 \%$ of cases were reported. Similarly, a study among community pharmacists by Oreagba et al, ${ }^{14}$ found that only $55 \%$ of respondents were aware of $\mathrm{PV}$, and of these, only $18 \%$ knew its correct definition. In addition, whereas $40 \%$ of respondents had obtained reports of ADRs from their clients at least once a month, only $20 \%$ of these had reported to relevant authorities, and only 3\% actually reported to the National Pharmacovigilance Centre. A study among patent medicine vendors (PMVs) in Ekiti State, Nigeria, ${ }^{15}$ reported very low ADRs reporting $(3.8 \%)$ and this was majorly attributed to lack of training on ADRs reporting (92.5\%) and fear of indictment $(61.3 \%)$. While these findings elucidate the importance of assessment of knowledge and practice of PV among healthcare providers by identifying the factors responsible for the weak PV system in the country, it emphasizes the need to conduct such studies in other parts of the country where such studies have not been carried out to know the local pattern and peculiarities. This would contribute significantly in generating vital information for designing appropriate strategies for developing strong PV systems and optimal ADRs reporting in such places. The knowledge, attitude and practice of PV among operators of pharmacies and patent medicine stores in Sokoto, Nigeria, have not been examined, thus making it necessary to conduct this study.

\section{MATERIALS AND METHODS}

\section{Study Design and Population}

A cross-sectional study was conducted among operators of pharmacies and patent medicine stores in Sokoto metropolis, North-Western Nigeria, from September to November 2017. Operators of pharmacies and patent medicine stores that were aged 18 years and above, and have worked for at least 6 months in the respective pharmacies and patent medicine stores were considered eligible for this study. The sample size was estimated at 246 using the Fisher's formula for calculating sample size for cross-sectional studies, ${ }^{16}$ a $20.0 \%$ prevalence of adverse drug reactions reporting among community pharmacists in a previous study, ${ }^{14}$ and a precision level of $5 \%$. This was adjusted upwards to 259 based on an anticipated participant response rate of $95 \%$.

The eligible participants were selected by a multistage sampling technique. At the first stage, Sokoto metropolis was divided into 12 business districts and 8 of them were selected by simple random sampling using the 
balloting option. At the second stage, the selection of pharmacies and patent medicine stores in each of the selected districts was done by a systematic sampling technique using the list of pharmacies and patent medicine stores in the respective districts to constitute the sampling frame (one of 2, and 1 of 3 pharmacies and patent medicine stores were selected respectively). At the third stage, the selection of participants in the selected pharmacies and patent medicine stores was done by a systematic sampling technique using the staff list in the respective pharmacies and patent medicine stores to constitute the sampling frame. One of every 3 eligible participants was selected in the selected pharmacies and patent medicine stores at the end of which 260 participants were selected.

\section{Data Collection and Analysis}

A standardized, structured, self-administered questionnaire was developed and used to obtain information on the participants' socio-demographic characteristics, and their knowledge, attitude and practice of pharmacovigilance. It was reviewed by researchers in the Department of Community Health, Usmanu Danfodiyo University, Sokoto, Nigeria. Corrections were made based on their inputs on content validity. The questionnaire was pretested on 20 operators of pharmacies and patent medicine stores in one of the business districts that were not selected for the study; some questions were rephrased for clarity based on the observations made during the pretesting. Five resident doctors assisted in questionnaire administration after being trained on the conduct of survey research, the objectives of the study, and questionnaire administration.

Data were analyzed using IBM Statistical Package for the Social Sciences (SPSS) Version 24.0 statistical computer software package. Respondents' knowledge of pharmacovigilance was scored and graded on a 10-point scale. One point was awarded for a correct response, while a wrong response or a non-response received no points. This gives a minimum score of ' 0 ' and a maximum score of ' 10 ' points. Those that scored $\geq 6$ of 10 points were considered as having 'good' knowledge, while those that scored $<6$ of 10 points were graded as having 'poor' knowledge. Frequency distribution tables were constructed; and cross tabulations were done to examine the relationship between categorical variables. The Chi- square test was used for bivariate analysis involving categorical variables. All levels of significance were set at $\mathrm{p}<0.05$.

\section{Ethical Consideration}

Institutional ethical clearance was obtained from the Ethical Committee of Sokoto State Ministry of Health, Sokoto, Nigeria. Permission to conduct the study in the pharmacies and patent medicine stores was obtained from the PMVs' union leaders and the owners of the selected pharmacies and patent medicine stores. The study objectives were explained to the participants and informed written consent was obtained from them before the data collection.

\section{RESULTS}

\section{Socio-demographic characteristics of respondents}

Two hundred and forty-nine out of the 260 questionnaires administered were completely filled and retrieved, giving a response rate of $95.8 \%$. The ages of the respondents ranged from 18 to 52 years, but majority of them $133(53.4 \%)$ were aged $20-29$ years. The majority of respondents were males $(189,75.9 \%)$, single $(163,65.5 \%)$, and practiced Islam as religion (140, $56.2 \%)$. Most of the respondents had diploma or bachelorette degree $(80.3 \%)$, and have practiced for less than 10 years $(86.7 \%)$. The majority of respondents were employees $(77.1 \%)$, and they practiced in patent medicine stores $(56.2 \%)$ as shown in Table 1.

Table 1: Socio-demographic characteristics of respondents

\begin{tabular}{ll}
\hline Variables & $\begin{array}{c}\text { Frequency (\%) } \\
\mathbf{n}=\mathbf{2 4 9}\end{array}$ \\
\hline Age group (years) & $33(13.3)$ \\
$<20$ & $133(53.4)$ \\
$20-29$ & $62(24.9)$ \\
$30-39$ & $21(8.4)$ \\
$\geq 40$ & \\
Sex & $189(75.9)$ \\
Male & $60(24.1)$ \\
Female & \\
Marital status & $163(65.5)$ \\
Single & $85(34.1)$ \\
Married & $1(0.4)$ \\
Separated & \\
Religion & $140(56.2)$ \\
Islam & $109(43.8)$ \\
Christianity & \\
Level of education & \\
Primary and below & $7(2.8)$ \\
Secondary & $42(16.9)$ \\
Post-secondary (diploma) & $124(49.8)$ \\
University (bachelorette) & $76(30.5)$ \\
Length of practice (years) & \\
1-9 & \\
$\geq 10$ & $215(86.3)$ \\
Place of practice & $34(13.7)$ \\
Pharmacy & \\
Patent medicine store & \\
Status & \\
Owner & \\
Employee & \\
\hline
\end{tabular}

\section{Awareness of pharmacovigilance by respondents}

The majority, $173(69.5 \%)$ of the 249 respondents had heard of pharmacovigilance (PV), with the most common source of information being lectures / seminars / workshops $(60.7 \%)$. About a tenth of respondents $(13.3 \%)$ also obtained information on PV from their colleagues (Table 2). 
Table 2: Awareness of pharmacovigilance by respondents

\begin{tabular}{ll}
\hline Variables & $\begin{array}{l}\text { Frequency } \\
(\%)\end{array}$ \\
\hline $\begin{array}{l}\text { Ever heard of pharmacovigilance } \\
(\mathbf{n}=\mathbf{2 4 9})\end{array}$ & \\
Yes & $173(69.5)$ \\
No & $76(39.5)$ \\
& \\
Main source of information & \\
(n= 173) & \\
Lectures / seminars / workshops & $105(60.7)$ \\
Journals / books & $16(9.2)$ \\
Radio / television & $16(9.2)$ \\
Newspaper / magazines & $13(7.5)$ \\
Colleagues & $23(13.3)$ \\
\hline
\end{tabular}

\section{Respondents' knowledge of pharmacovigilance}

Only $43(17.3 \%)$ of the 249 respondents had good knowledge of pharmacovigilance (PV). About a third knew the correct definition of PV $(36.1 \%)$ and its main purpose $(31.3 \%)$. Also, about a third knew the correct definition of an adverse drug reaction $(35.7 \%)$, and that all healthcare providers should report an ADR (36.1\%). Although, the majority of respondents $(64.3 \%)$ knew the organization in charge of adverse drug reactions (ADRs) reporting, less than half of them knew the benefits of ADRs reporting (38.2\%), and that all ADRs should be reported $(41.4 \%)$ as shown in Table 3 . There was no association between good knowledge of pharmacovigilance and any of the respondents' sociodemographic variables.

Table 3: Respondents' knowledge of pharmacovigilance

\begin{tabular}{lc}
\hline Variables & $\begin{array}{c}\text { Frequency (\%) } \\
(\mathbf{n}=\mathbf{2 4 9})\end{array}$ \\
\hline Knowledge of pharmacovigilance & $90(36.1)$ \\
Knew the correct definition of pharmacovigilance & $78(31.3)$ \\
Knew the main purpose of pharmacovigilance & $89(35.7)$ \\
Knew the correct definition of an adverse drug reaction & $103(41.4)$ \\
Knew that all adverse drug reactions should be reported & $160(64.3)$ \\
Knew that NAFDAC is the organization in charge of ADR reporting in Nigeria & $90(36.1)$ \\
Knew that all healthcare providers should report an ADR & $42(16.9)$ \\
Knew that the yellow form is used in reporting adverse drug reactions & $113(45.4)$ \\
Knew the information that should be entered into the ADR reporting form & $39(15.7)$ \\
Knew where ADR reporting form can be obtained from, and where it should be submitted \\
after completing it. & $95(38.2)$ \\
Knew the benefits of ADR reporting & \\
Knowledge grade & $43(17.3)$ \\
Good & $206(82.7)$ \\
Poor &
\end{tabular}

NAFDAC: National Agency for Food and Drug Administration and Control

ADR: Adverse drug reaction

\section{Respondents' attitude towards pharmacovigilance}

Most of the 249 respondents showed positive attitude towards pharmacovigilance, as they believed that adverse drug reactions (ADRs) reporting is a professional obligation $(232,93.2 \%)$, and necessary (247, 97.6\%). Also, most of them believed that ADRs reporting will increase clients' safety $(240,96.4 \%)$ and should be made mandatory $(222,89.2 \%)$. Most of them also believed that pharmacovigilance should be taught in detail to healthcare providers $(241,96.8 \%)$ and were willing to participate in ADRs reporting $(235,95.6 \%)$ as shown in Figure 1.

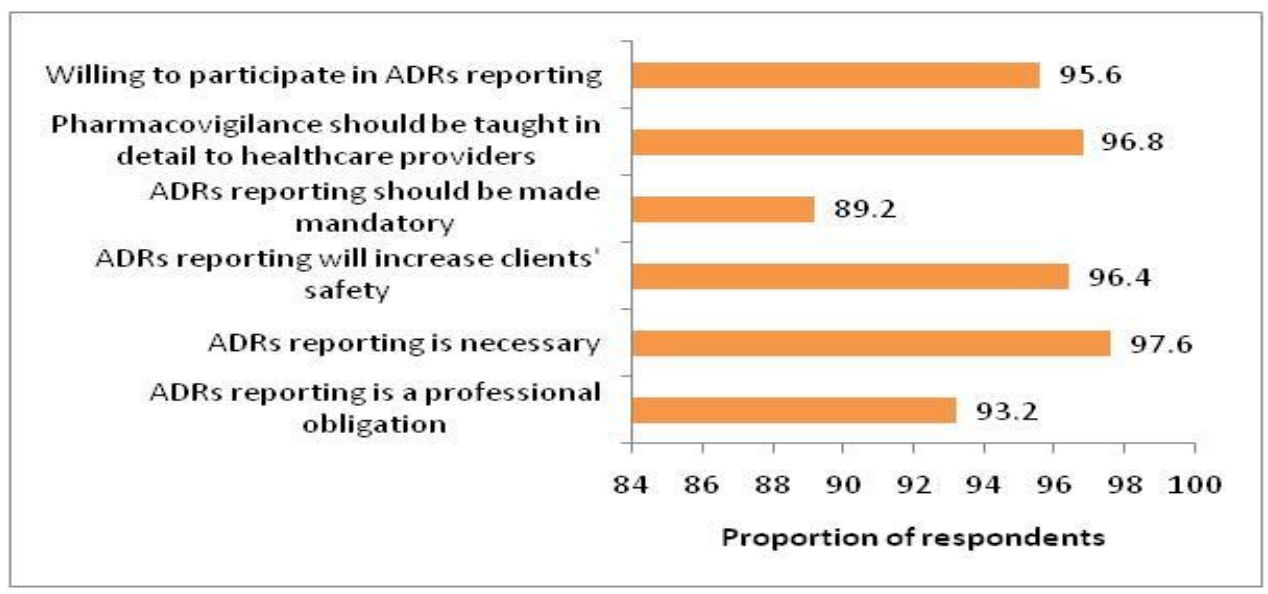

Figure 1: Respondents' attitude towards pharmacovigilance 


\section{Respondents' pharmacovigilance practices}

Only about a quarter of respondents had attended a seminar on adverse drug reaction (ADR) reporting (28.5\%), and had seen an ADR reporting form (26.1\%). Close to half, $107(43.0 \%)$ of the 249 respondents had observed an ADR in clients; of these, only about half (52.3\%) reported the ADR observed, mostly to the shop owners (44.6\%), their colleagues $(16.1 \%)$ and supervisors $(14.3 \%)$; only about a tenth $(12.8 \%)$ of them reported formally to either the State NAFDAC office or Zonal Pharmacovigilance Centre. The most common reasons for not reporting the ADRs observed in clients were that they did not know where and how to report $(51.0 \%)$, and unavailability of reporting forms in their pharmacies / stores (23.5\%) as shown in Table 4.

Table 4: Respondents' pharmacovigilance practices

\begin{tabular}{|c|c|}
\hline Variables & Frequency $(\%)$ \\
\hline \multicolumn{2}{|l|}{ Ever attended a seminar on ADR reporting $(n=249)$} \\
\hline Yes & $79(28.5)$ \\
\hline No & $178(71.5)$ \\
\hline \multicolumn{2}{|l|}{ Ever seen an ADR reporting form $(n=249)$} \\
\hline Yes & $65(26.1)$ \\
\hline No & $184(73.9)$ \\
\hline \multicolumn{2}{|l|}{ Ever observed an ADR in clients $(n=249)$} \\
\hline Yes & $107(43.0)$ \\
\hline No & $142(57.0)$ \\
\hline \multicolumn{2}{|l|}{ Types of ADR seen $(n=107) *$} \\
\hline Vomiting & $50(45.9)$ \\
\hline Skin rashes & $66(60.6)$ \\
\hline Itching & $33(30.3)$ \\
\hline Eye symptoms & $18(16.5)$ \\
\hline Body swelling & $16(14.7)$ \\
\hline Others & $97(89.0)$ \\
\hline \multicolumn{2}{|l|}{ Ever reported an ADR observed in clients $(n=107)$} \\
\hline Yes & $56(52.3)$ \\
\hline No & $51(47.7)$ \\
\hline \multicolumn{2}{|l|}{ Where / who observed ADR was reported $(n=56)$} \\
\hline Colleagues & $9(16.1)$ \\
\hline Supervisor & $8(14.3)$ \\
\hline Owner of shop & $25(44.6)$ \\
\hline Drug distributor & $7(12.5)$ \\
\hline State NAFDAC office & $3(5.7)$ \\
\hline Zonal Pharmacovigilance Centre & $4(7.1)$ \\
\hline \multicolumn{2}{|l|}{ Main reason for not reporting observed ADR $(n=51)$} \\
\hline Did not know where and how to report & $26(51.0)$ \\
\hline Did not consider it important & $9(17.6)$ \\
\hline To maintain clients' confidentiality & $2(3.9)$ \\
\hline Reporting forms not available in the pharmacy / store & $12(23.5)$ \\
\hline Fear of legal liability & $2(3.9)$ \\
\hline
\end{tabular}

\section{DISCUSSION}

This study assessed the knowledge, attitude and practice of pharmacovigilance among operators of pharmacies and patent medicine stores in Sokoto metropolis, Nigeria. The high educational attainment of the respondents in this study with most of them $(80.3 \%)$ having diploma or bachelorette degree is not surprising considering the fact their job entails being able to identify the drugs requested by clients, read the instructions on the drug label and counsel their clients on the dosage regimen, the likely side effects, and what to do should they experience any adverse drug reaction. This finding is in agreement with the finding in studies conducted among operators of pharmacies and patent medicine stores in other cities in Nigeria, as they majorly reported high educational attainment among the respondents. ${ }^{17-19}$

Whereas, awareness of pharmacovigilance is higher among the respondents in this study (69.5\%) as compared to the finding in a study among community 
pharmacists in Lagos, South West Nigeria ${ }^{14}$ that reported that only about half $(55.0 \%)$ of respondents were aware of $\mathrm{PV}$, it is much lower than the very high awareness $(100 \%)$ reported in another study conducted among pharmacists in two states in South-eastern Nigeria. ${ }^{20}$ The wide variation in the awareness of PV among operators of pharmacies and patent medicine stores across the country underscores the need for the National Agency for Food and Drug Administration and Control to organize regular sensitization campaigns on PV across the country.

The poor knowledge of PV among the respondents in this study with less than a fifth of them $(17.3 \%)$ having good knowledge of PV, and only about a third knowing the correct definition of PV and its main purpose is surprising in view of their high educational attainment. It is also surprising that only about a third of the respondents in this study knew the correct definition of an adverse drug reaction $(35.7 \%)$, and that the yellow form is used in reporting adverse drug reactions $(36.1 \%)$. However, the main cause for concern is the generally poor knowledge of pharmacovigilance and adverse drug reactions reporting in studies conducted among community pharmacists and patent medicine vendors in Nigeria ${ }^{14,15,20}$ and other developing countries including South Africa, ${ }^{9}$ Jordan, ${ }^{6}$ Yemen, ${ }^{21}$ India, ${ }^{4}$ and Saudi Arabia, ${ }^{22}$ as they imply poor sensitization of healthcare providers on PV as a result of the weak PV systems in these countries.

While the finding of close to half of the respondents in this study (43.0\%) ever observing an adverse drug reaction in clients suggests a high burden of the problem in Sokoto, Nigeria, the finding of about half $(52.3 \%)$ of those that had observed an ADR in clients reporting it, with only a tenth $(12.8 \%)$ of these reporting formally to either the State NAFDAC office or Zonal

\section{REFERENCES}

1. World Health Organization (WHO). WHO guidelines on safety monitoring of herbal medicines in pharmacovigilance systems. Geneva, Switzerland: WHO; 2004. Available from: http://apps.who.int/medicinedocs/documents/s7148e/s7148e. pdf [Last accessed on 2018 August 21].

2. World Health Organization (WHO). Quality Assurance and Safety of Medicines Team. Safety of medicines: a guide to reporting adverse drug reactions: why health professionals need to take action. Geneva, Switzerland: WHO; 2002. Available from: http://www.who.int/iris/handle/10665/67378 [Last accessed on 2018 August 21].

3. Wu T, Jen M, Bottle A, Molokhia M, Aylin P, Bell D et al. Ten-year trends in hospital admissions for adverse drug reactions in England 1999-2009. J Royal Soc Med 2010; 103:239. doi: 10.1258/jrsm.2010.100113.

4. Prakasam A, Nidamanuri A, Kumar S. Knowledge, perception and practice of pharmacovigilance among community pharmacists in South India. Pharmacy Practice (Internet) 2012; 10(4):222-6.

5. Almandil NB. Healthcare professionals' awareness and knowledge of adverse drug reaction and pharmacovigilance. Saudi Med J 2016; 37(12):1359-64.

6. Suyah M, Farah D, Farha RA. Pharmacists' knowledge, practice and attitude towards pharmacovigilance and adverse drug reactions reporting process. Saudi Pharm J 2015; 23:147-53.

7. Choi HL, Nwokike J, Boni A, Lee D. Comprehensive assessment of pharmacovigilance systems and their
Pharmacovigilance Centre is worrisome as it indicates a very weak PV system in Sokoto State, Nigeria (as most of the pharmacies and patent medicine stores in the state are located in Sokoto metropolis). This is obvious in view of the positive attitude towards PV by most of the respondents (particularly their willingness to participate in ADRs reporting), and the fact that only about a quarter of respondents $(28.5 \%)$ had attended a seminar on ADR reporting, and the main reasons cited for not reporting the ADRs they had observed in their clients were that they did not know where and how to report (51.0\%), and unavailability of ADRs reporting forms in their pharmacies / stores. It is therefore imperative for the Sokoto State NAFDAC office, in collaboration with the National and Zonal Pharmacovigilance Centers to sensitize the populace and train healthcare providers (particularly, operators of pharmacies and patient medicine stores) on PV and ADRs reporting in order to revitalize the PV system in the state.

\section{CONCLUSION}

This study showed poor knowledge of pharmacovigilance (PV) and sub-optimal adverse drug reactions (ADRs) reporting (despite positive attitude towards it) by operators of pharmacies and patent medicine stores in Sokoto metropolis, Nigeria. Sensitization of the populace and training of healthcare providers on PV and ADRs reporting are necessary for revitalizing the PV system in Sokoto State, Nigeria.

\section{ACKNOWLEDGEMENTS}

The authors appreciate the patent medicine vendors' union leaders, the owners of the pharmacies and patent medicine stores that were selected for the study, and all the operators that participated in the study for their cooperation. performance in sub-Saharan Africa. Systems for improved access to pharmaceuticals and services (SIAPS) program. Arlington, VA: Management Services for Health; 2012. Available from: http://apps.who.int/medicinedocs/en/d/Js21933en/ [Last accessed on 2018 August 21].

8. Katusiime B, Semakula D, Lubinga SJ. Adverse drug reaction reporting among healthcare workers at Mulago National Referral and Teaching Hospital in Uganda. Afr Health Sci 2015; 15(4):1308-17.

9. Joubert MC, Naidoo P. Knowledge, perceptions and practices of pharmacovigilance amongst community and hospital pharmacists in a selected district of North West Province, South Africa. Health SA Gesondheid 2016; 21: 238-44.

10. Wafula FN, Miriti EM, Goodman CA. Examining characteristics, knowledge and regulatory practices of specialized drug shops in sub-Saharan Africa: a systematic review of the literature. BMC Health Serv Res 2012; 12:223.

11. National Primary Health Care Development Agency (NPHCDA). Draft essential childhood medicines scale-up plan. Abuja, Nigeria: Federal Ministry of Health, Nigeria; 2011. doi: $10.1080 / 17437199.2011 .587961$.

12. Adebayo AM, Asuzu MC. Utilization of a community based health facility in a low-income urban community in Ibadan, Nigeria. Afr J Prim Health Care Fam Med 2015; 7. doi: 10.402/phcfm.v $7 ; 1.735$ 
13. Ohaju-Obodo JO, Iribhogbe OI. Extent of pharmacovigilance among resident doctors in Edo and Lagos States of Nigeria. Pharmacoepidemiol Drug Saf 2010; 19(2):191-5.

14. Oreagba IA, Ogunleye OJ, Olayemi SO. The knowledge, perceptions and practice of pharmacovigilance amongst community pharmacists in Lagos State, South West Nigeria. Pharmacoepidemiol Drug Saf 2011; 20(1):30-5.

15. Awodele O, Adeniran A, Awodele DF. Pharmacovigilance amongst patent medicine vendors (PMVs) in Ekiti State, Nigeria. Int J Risk Saf Med 2012; 24(2):65-72.

16. Araoye MO. Research methodology with statistics for health and allied social sciences. Ilorin: Nathadex; 2004

17. Okonkwo AD, Okonkwo UP. Patent medicine vendors, community pharmacists and STI management in Abuja, Nigeria. Afr Health Sci 2010; 10(3):253-65.

18. Auta A, Omale S, Folorunsho TJ, David S, Banwat SB Medicine vendors: self medication practices and medicine knowledge. N Am J Med Sci 2012; 4:24-28.
19. Tobin-West CI, Adeniji FO. Knowledge and practices of patent medicine vendors in Rivers State, Nigeria: implications for malaria control in rural and sub-urban communities. Indian J Pharm Practice 2012; 5:34-39.

20. Udoye JA, Ozolua R, Nwokike J. Assessment of the knowledge, attitude and practice of pharmacovigilance by pharmacists in two states in South-eastern Nigeria. Trop J Pharm Res 2018; 17(5):937-45.

21. Al-Worafi YM, Kassab YW, Alseragi WM, Almutairi MS, Ahmed A, Ming LC et al. Pharmacovigilance and adverse drug reaction reporting: a perspective of community pharmacists and pharmacy technicians in Sana'a, Yemen. Ther Cli Risk Mang 2017; 13:1175-81.

22. Mahmoud MA, Alswaida Y, Alshammari T, Khan TM, Alrasheedy A, Hassali MA, Aljadhey H. Community pharmacists' knowledge, behaviors and experiences about adverse drug reaction reporting in Saudi Arabia. Saudi Pharm J 2014; 22(5):411-18. 